\title{
Filme documentário, leitura documentarizante ${ }^{1}$
}

////////////////// $:$ Roger Odin ${ }^{2}$

1. Texto original: ODIN, Roger. "Film documentaire, lecture documentarisante". In: ODIN, R.; LYANT, J. C. (Ed.). Cinémas et réalites. Saint-Etienne: Université de Saint-Etienne, 1984, p. 263-277. Tradução de Samuel Paiva (professor adjunto do Departamento de Artes e Comunicação e do Programa de Pós-Graduação em Imagem e Som da Universidade Federal de São Carlos).

2. Professor de ciência da informação e da comunicação na Universidade de Paris III Sorbonne Nouvelle, onde dirige o Instituto de Pesquisa de Cinema e Audiovisual. É autor, entre outros, de Cinéma et production de sens (1990) et De la fiction (2000). 


\section{Resumo}

Refletir sobre as relações entre cinema e realidade não é, certamente, tentar distinguir o espaço do documentário daquele da ficção, uma vez que a oposição ao filme de ficção tornouse o critério de definição privilegiado do filme documentário. Notando a existência, no espaço de leitura dos filmes, de uma leitura documentária ou, mais exatamente, de uma leitura documentarizante, pensamos que existe um conjunto de filmes que se mostram como documentário (todo o problema consiste precisamente em estudar como se efetua essa exibição).

\section{Palavras-chave}

documentário, ficção, leitura documentarizante

\section{Résumé}

Réfléchir sur la relation entre le cinéma et la réalité n'est pas, bien sûr, tenter de distinguer l'espace du documentaire de celui de la fiction, au point que l'opposition avec le film de fiction est devenu le critère de définition privilégié du film documentaire. Prenant acte l'existence, dans le espace de la lecture des films, d'une lecture documentaire ou, plus exactement, d'une lecture documentarisante, nous pensons qu'il y a un ensemble de films que s'affiche comme documentaire (tout le problème est précisément étudier comment s'effetue cet affichage).

\section{Mots-clés}

documentaire, fiction, la lecture documentarisante 
3. Algumas citações para sustentar essa afirmação: "Documentário: gênero cinematográfico que rejeita a ficção para tornar presente a própria realidade" (BESSY, M.; CHARDON, J-L. Dictionnaire du cinéma et de la tèlevision, p. 124); "Documentário: que tem o caráter de um documento ou que tem base sobre documentos. Filme documentário, por oposição a filme de ficção" (Dictionnaire Robert); "Um documentário é um filme no qual não é identificável a ficção" (BURCH, N. "Two recent British films and the documentary ideology", Screen, v. 19 , n. 2, p. 122, 1978); "Filme documentário: filme geralmente de curta ou média metragem, de caráter informativo ou didático, que apresenta documentos autênticos sobre um setor da vida ou da atividade humana ou sobre o mundo natural" (Trésor de la langue française, Dictionnaire de la langue du XIX ${ }^{\mathrm{e}}$ et du XX $\mathrm{XX}^{\mathrm{e}}$ siècle, CNRS; Klincksieck).

4. "Onde termina o documento? Em parte alguma, pois, sem dúvida, todo filme pode, na
Com algumas exceções, os textos reunidos aqui estão voltados para o problema sobre as relações entre cinema documentário e cinema de ficção.

Não seria de surpreender: refletir sobre as relações entre cinema e realidade não é, certamente, tentar distinguir o espaço do documentário daquele da ficção, uma vez que a oposição ao filme de ficção tornou-se o critério de definição privilegiado do filme documentário. ${ }^{3}$

Entretanto, o que se coloca em destaque nesta análise são as dificuldades insuperáveis com que nos debatemos quando tentamos precisar essa oposição.

Alguns autores ressaltam assim esse tipo de "banalidade" (GAUTHIER): o documentário não tem o privilégio de referirse à realidade. A filmagem em exterior faz de todo western um documentário sobre as paisagens que lhe servem de cenário (LEUTRAT) e "é por meio dos filmes indianos, dos westerns, dos policiais e dos filmes de caratê" que os espectadores africanos "aprenderam como se vestem os homens e as mulheres de outros países", “como se constrói um avião”... etc. (JACQUINOT).

Todo filme de ficção pode então ser considerado, sob um certo ponto de vista, como um filme documentário. ${ }^{4}$

De todo modo, o problema se complica quando se descobre que é possível sustentar de maneira legítima o inverso: na medida em que "o filme industrial, o filme científico, como o documentário, 
condição de ser examinado sob a perspectiva adequada, revelar um

aspecto documentário.

A fronteira entre documentário e ficção

é por natureza evanescente; os critérios

discriminativos não se sustentam. No máximo, podem distinguir níveis de penetração do aspecto documentário nos filmes de ficção" (TARDY, M.

Image et Son, n. 183, p. 63).

"Todo filme de ficção é um

documento sobre seu autor, seus atores, sua época [...]" (SONET, H. Cinéma et réalité. Bruxelles, p. 15).

5. A expressão "todo filme é um filme de ficção", citada em Esthétique du film, provém

de: METZ, C. "Le signifiant imaginaire", Communications, 23,1975 , p. 31.

6. Quer dizer que nós nos situamos aqui em uma perspectiva de uma semiologia da leitura, e não de uma semiologia da realização; é certo que o problema do cinema

documentário demandaria ser estudado, igualmente, na perspectiva de uma semiologia da realização. Não estamos convencidos de que

essas duas abordagens estejam isoladas como a frente e o verso de um mesmo procedimento (dito de outra maneira, não acreditamos na ficção de um "modelo neutro"); contentamo-nos com um exemplo particularmente importante para aqueles que se interrogam sobre

o documentário: no espaço da realização, o estado do pró-fílmico dificilmente coloca o problema; sabemos, trata-se de um cenário de estúdio ou de um cenário real, estão sujeitos à lei que deseja que, por sua matéria de expressão (imagem em movimento, som), todo filme 'desrealize' [irréalise] aquilo que representa", "todo filme é um filme de ficção" (METZ, 1975, p. 31 apud AUMONT et al, 1983, p. 70-71). ${ }^{5}$

A própria noção de referência à realidade não se coloca sem dificuldade: ela restringe aquilo que se pode entender por realidade e se engaja, desse modo, no delicado debate filosófico entre Real e Imaginário, Verdadeiro e Falso (a análise de Moi, un noir de M. Scheinfeigel testemunha a precariedade dessa distinção), em uma interrogação sobre "a honestidade, a coragem, a profundidade" do trabalho do cineasta (P. Warren, em "La technique n'est pas innocente"), sobre o valor dos modelos de realidade convocados (cf. G. Bettetini e G. Combes, a propósito de Flaherty) ou, mais radicalmente ainda, sobre o estatuto mesmo do que se vê (J. Aumont define claramente a questão no início de seu artigo sobre Vertov).

A conclusão a que, em geral, chegamos com essas observações é que "podemos nos questionar se realmente existe um gênero documentário" (GAUTHIER, 1965, p. 7); raros são os autores dessa obra que, ao menos, não colocam a questão, insistindo sobre a falta de critérios "suscetíveis de constituir o documentário como um gênero" (GARDIES; MARIE), sobre “a fragilidade de uma tal categorização" (MARSOLAIS) e também sobre sua inutilidade (LEUTRAT).

A posição que nós queremos defender aqui é um pouco diferente. Notando a existência, no espaço de leitura dos filmes ${ }^{6}$, de uma leitura documentária ou, mais exatamente (perdoem a indignidade do neologismo), de uma leitura documentarizante - quer dizer, de uma leitura capaz de tratar todo filme como documento - , nós tentaremos, em um primeiro tempo, caracterizar essa leitura e, depois, efetuaremos um certo número de considerações sobre seu funcionamento, para chegarmos, enfim, aos critérios distintivos dos próprios filmes documentários, porque nós insistimos em pensar que existe um conjunto de filmes que se exibe, que se mostra como documentário (todo o problema consiste precisamente em estudar como se efetua essa exibição). 
de um ator que interpreta um personagem ou de um personagem real; em contrapartida, no espaço da leitura, esse tipo de questão é muito frequentemente indeterminável.

Para outro exemplo ilustrativo da necessidade de distinguir essas duas abordagens semiológicas, cf. nosso artigo: "A propos d'un couple de concepts: son in vs son off...", Linguistique et sémiologie ("Semiologie"), n. 6, PUL, p. 98.

7. Os editores mantiveram a numeração de tópicos do texto original.

8. Observem que falaremos de leitura fictivizante, e não de leitura ficcionalizante; é que para nós esses dois conceitos não se confundem: toda leitura ficcionalizante é fictivizante, mas não o inverso; ou seja, o processo de ficcionalização

é mais complexo que o processo

de fictivização que ele integra:

a leitura ficcionalizante assume especialmente, além da fictivização, a execução da operação de mise en phase. Sobre essa noção, cf. ODIN,

R. "Mise en phase, déphasage et performativité dans Le Tempestaire de Jean Epstein", Communications, n. 38 ("Enonciation et cinéma"), p. 218-226, 1983, e "Pour une sémiopragmatique du cinéma, Iris, n. 1, 1983 , p. $75-76$. [Nota do tradutor: a expressão mise en phase, que aqui

distingue as duas operações fictivizante e ficcionalizante -, não é facilmente traduzível. Entretanto, encontra uma explicação em Robert Stam, que, referindo-se aos processos semiopragmáticos propostos por Roger Odin, especificamente sobre a operação em questão, afirma: "mise

\section{Leitura documentarizante vs leitura fictivizante ${ }^{7}$}

Para caracterizar a leitura documentarizante, parece-nos operatório proceder por oposição à leitura fictivizante ${ }^{8}$, todo filme podendo ser submetido por seu "leitor", 9 a uma ou a outra dessas leituras ${ }^{10}$.

\subsection{Primeira abordagem}

A única solução, ao que parece, para evitarmos a recaída nas aporias precedentes é nos estabelecermos não sobre a realidade ou não realidade do representado, mas sobre a imagem que o leitor faz do Enunciador (por enquanto, nós definiremos - de uma forma um tanto vaga; depois se verá o porquê - o Enunciador como aquele que é observado na origem da comunicação fílmica). Essa maneira de abordar o problema não é nova.

É assim que um certo número de teóricos pertencentes à linguística textual [textlinguistik] alemã, ou inspirados nela, propôs caracterizar o espaço literário (a literariedade) pelo modo como o leitor constrói a imagem do autor: o leitor de um texto literário “espera que o autor tenha fictivizado o seu papel, que suas asserções não devam então ser tomadas como afirmações segundo sua verdade na semântica referencial" (SCHMIDT, 1978, p. 27).

Pouco importa, para nosso propósito, que S. J. Schmidt assimile indevidamente "literariedade" [litterarité] e "fictividade" [fictivité $]^{11}$; o próprio processo parece fundamentalmente correto. Nessa perspectiva, poderia se considerar em seguida uma sugestão de K. Hamburger (1968) - que por sua vez empresta essa dupla de conceitos de K. Bühler (1934) - , para definir as leituras fictivizantes e documentarizantes pela seguinte dicotomia:

\begin{tabular}{c|c}
\hline Leitura fictivizante & Leitura documentarizante \\
\hline O leitor constrói & O leitor constrói \\
um eu-origem fictício & um eu-origem real \\
\hline
\end{tabular}


en phase (literalmente "colocação em fase', ou o gradual engajamento do espectador), a operação que põe todas as instâncias fílmicas a serviço da narração, mobilizando o trabalho rítmico e musical, o jogo de olhares e o enquadramento, para fazer que

o espectador vibre ao ritmo dos acontecimentos fílmicos" (STAM,

R. Introdução à teoria do cinema. Tradução de Fernando Mascarello Campinas: Papirus, 2003, p. 280-281).]

9. Para uma justificativa da utilização dessa denominação, em vez da denominação

"espectador", cf. nosso artigo "Pour une sémio-pragmatique du cinéma, Iris, n. 1, 1983, p. 74-75.

10. Evidentemente, não é o caso aqui de pretender que existam somente dois tipos de leitura no espaço cinematográfico; à

"leitura fictivizante" e à "leitura documentarizante", que nos interessam neste artigo, já se pode acrescentar a "leitura estetizante", característica do campo artístico.

11. Para uma crítica dessa assimilação, cf. SEARLE, J. "Le statut logique du discours de la fiction”. In: SEARLE, J. Sens et expression. Paris; Minuit, 1979, p. 101-103 ("Distinction entre fiction et littérature").

12. Na perspectiva de Benveniste ([s.d.], p. 240), o "discurso" se opõe à "história" como "toda enunciação conjugando um locutor e um ouvinte".
Esse sistema de oposições não é, entretanto, para nós, totalmente satisfatório.

\subsection{Segunda abordagem}

Parece-nos, com efeito, que o que constitui a leitura fictivizante não é tanto a construção de um "eu-origem fictício", mas, mais radicalmente, a recusa do leitor em construir um "eu-origem".

Partindo dessa constatação, poderia ser tentador deduzir que a leitura fictivizante se remete à enunciação "histórica" de Benveniste ([s.d.], p. 241): "Ninguém fala aqui, os eventos parecem falar por eles mesmos". É necessário observar, entretanto, que aquilo que Benveniste denomina de enunciação "histórica" não está no mesmo nível daquilo que nos interessa, ou seja, a ausência de construção de um "eu-origem"; o que M. Colin nota da seguinte maneira: "nada parece justificar a utilização das noções de Benveniste aqui". A "falta" enunciativa de que falamos tem, com efeito, a propriedade de poder se manifestar mesmo quando o texto funciona com uma estrutura de enunciação marcada (textos em primeira pessoa), mesmo quando o texto pertence à categoria do discurso ${ }^{12}$. É que aquilo que é visado pela oposição "história" vs "discurso" são as enunciações enunciadas; enquanto a oposição que nós tentamos definir concerne ao próprio fazer enunciativo um fazer enunciativo que é justamente posto, no quadro da leitura fictivizante, como ausente $(\varepsilon=0)$.

Com o propósito de melhor esclarecer esse ponto, mostraremos as conclusões dessa segunda abordagem não com um quadro, mas com uma "árvore" (que tem a vantagem de manifestar mais claramente a hierarquização dos níveis enunciativos considerados). 
13. Benveniste enumera algumas marcas para o texto escrito: formas verbais, formas pronominais...

14. Sobre este ponto, cf. nosso artigo "Pour une sémio-pragmatique du cinéma”, Iris, n. 1, 1983.

15. Abreviação de "nota bene", expressão que indica uma observação ao texto.

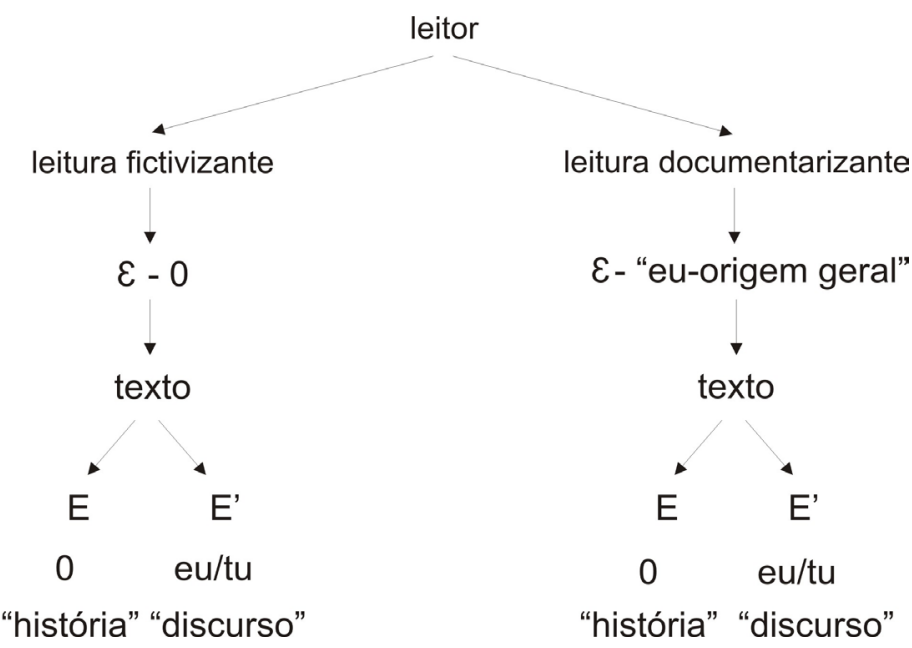

Notarão, seguindo essa descrição, que a oposição "história" vs "discurso" é um efeito do Texto (a oposição se coloca através das marcas inscritas no enunciado ${ }^{13}$ ), enquanto a oposição leitura fictivizante vs leitura documentarizante é um efeito do posicionamento do leitor face ao filme, o resultado de uma operação externa ao filme: uma operação estritamente pragmática.

Encontra-se aqui aquilo que nós temos tentado mostrar de outras maneiras: a necessidade de colocar a pragmática no posto de comando da análise, porque é ela que rege, em primeira instância, o modo de leitura posto em execução frente a um filme ${ }^{14}$.

$N \cdot B^{15} .:$ A análise das enunciações enunciadas não pode, evidentemente, se reduzir apenas a um sistema de oposições: "história" vs "discurso"; o artigo de F. Casetti ("L'apparition du réel, ou faire regarder, regarder ensemble, revoir") mostra bem que a tipologia prevista é muito mais complexa e deve levar em conta diferentes eixos de estruturação; mas esse não é o nosso problema no momento.

\subsection{Terceira abordagem}

Convém agora precisar aquilo que se coloca como base da noção de "eu-origem real".

Para isso, poder-se-ia recorrer à noção de "enunciação indireta" tal qual foi definida por J. Searle (1979) em seu artigo sobre "Le statut logique du discours de la fiction" (diz-se que essa definição 
16. Para uma definição do ato de asserção, cf. SEARLE, J. Les actes de langage. Hermann, 1972. Cap. III.

17. "O critério de identificação que permite reconhecer se um texto é ou não uma obra de ficção deve necessariamente residir nas intenções ilocutórias do autor" (SEARLE, 1979, p. 109). [Nota do tradutor: para Searle, existem

cinco tipos de atos ilocutórios: assertivos, diretivos, compromissivos, expressivos e declarações. Já os atos de fala indiretos estão relacionados a sentenças nas quais o falante quer

significar não apenas o que diz mas também algo mais. Em suas palavras: "O problema levantado pelos atos de fala indiretos é o de saber como é possível para o falante

dizer uma coisa, querer significá-

la, mas também querer significar algo mais. E, já que a significação consiste, em parte, na intenção de produzir no ouvinte a compreensão, grande parte desse problema é saber

como é possível para o ouvinte compreender o ato de fala indireto

quando a sentença que ouve e compreende significa algo mais" (SEARLE, J. Os actos de fala: um ensaio de filosofia da linguagem. Coimbra: Andina, 1981, p. 49).]

18. Índices = signos não intencionais; sinais = signos intencionais; $\mathrm{cf}$. MOUNIN, G. Introduction à la sémiologie. Paris: Minuit, 1970, p. 13; mesmo sistema de oposições em Buyssens e Prieto. se estabelece sobre o ato ilocutório da asserção $)^{16}$, mas as condições postas para caracterizar o ato de assertar nos parecem bastante restritivas para serem aplicadas à leitura documentarizante.

Dois pontos nos parecem essencialmente problemáticos.

Em sua definição de asserção, Searle mobiliza noções de verdade e sinceridade (regras 1 e 4). Ora, é certo que um filme permanece como um documentário mesmo quando se coloca sobre ele um julgamento negativo no que concerne à verdade do representado e à sinceridade de seu autor, mesmo quando aquilo que ele diz é falso ou mentiroso. Todo documentário não é, além disso, de uma certa forma, segundo a bela fórmula de A. Varda, um documenteur $[$ menteur $=$ mentiroso $]$ ?

Mas há mais; a definição de "enunciação indireta” proposta por J. Searle (1979) se estabelece explicitamente sobre a pressuposição de uma certa intenção, da parte do autor, de enunciar ${ }^{17}$; ora, o recurso a essa pressuposição nos parece duplamente inútil.

De uma parte, porque o filme pode ser lido como um "documento" sem que o leitor pressuponha a equivalência entre Enunciador e "autor"; é o caso, por exemplo, de quando o leitor decide ler um filme como um reflexo da sociedade na qual ele foi produzido. Não é necessário então reduzir o Enunciador de um filme a seu "autor" (admitindo-se que se possa atribuir um conteúdo preciso à noção de “autor” no cinema).

De outra parte, porque um filme pode ser lido como um “documento" sem que o leitor pressuponha qualquer “intenção documentária" por parte do Enunciador. Poderíamos aqui nos contentar com a remissão ao exemplo anterior; mas, geralmente, é possível dizer que esse é o caso quando a leitura se efetua em termos de índices, e não em termos de sinais $^{18}-$ é isso que evidentemente ocorre quando o leitor toma o filme como revelador da personalidade profunda de seu realizador (= leitura do tipo psicanalítica).

Nessas condições, como se vê, a noção de “eu-origem real” tornase um tanto inadequada. Ela deixa de compreender claramente que 
19. P. Bange fala de "pessoa real"; cf. "Pragmatique et littérature". In: BANGE, P. et al. Logique, argumentation, conversation. Berna: Peter Lang, 1983, p. 156. se lida com um Sujeito que funciona por meio de um modo de intencionalidade; quer dizer, que se lida com uma pessoa ${ }^{19}$.

De fato, o único critério que, nos parece, deve ser mantido para caracterizar aquilo que advém na hora de executar a leitura documentarizante é que o leitor constrói a imagem do Enunciador, pressupondo a realidade desse Enunciador.

Uma tal especificação da leitura documentarizante permite compreender por que mesmo "um objeto irreal não prejudica o caráter de realidade do enunciado" (BANGE, 1978, p. 138); por que um leitor, mesmo consciente do caráter mais ou menos fantasioso das reconstituições e das antecipações de J. Painlevé em Voyage dans le ciel e em Notre planète la terre, não deixa de considerar esses dois filmes, até então, como "filmes científicos" - "filmes científicos" questionáveis cientificamente falando, mas ainda assim filmes científicos (= filmes que pertencem ao "gênero" científico) -; por que O homem de Aran continua sendo lido como documentário mesmo se não ignoramos nada das liberdades tomadas por R. Flaherty com a realidade da vida cotidiana dos pescadores-cultivadores dessa ilha (cf. o artigo de G. Combes: "Le cinéma d'Aran").

O que estabelece a leitura documentarizante é a realidade pressuposta do Enunciador, e não a realidade do representado.

O sistema de oposições entre leitura fictivizante e leitura documentarizante será então formulado da seguinte maneira:

\begin{tabular}{c|c}
\hline Leitura fictivizante & Leitura documentarizante \\
\hline $\begin{array}{c}\text { O leitor recusa a construção } \\
\text { de um "eu-origem" }\end{array}$ & $\begin{array}{c}\text { O leitor constrói um } \\
\text { Enunciador pressuposto real }\end{array}$ \\
\hline
\end{tabular}

\section{Funcionamento da leitura documentarizante}

Tentando definir o que estabelece a leitura documentarizante, nós podemos de agora em diante nos interrogar sobre suas modalidades de funcionamento. 
20. Diz-se que Roland Barthes propôs denominar de bathmologie a ciência que estudaria esse

"escalonamento da linguagem" (Roland Barthes par Roland Barthes,

Seuil, 1975, p. 71). [Nota do tradutor: na tradução de L. PerroneMoisés do livro de Roland Barthes para o português, encontramos a seguinte explicação do conceito de "batimologia": "Todo discurso está preso ao jogo dos graus. Podemos chamar esse jogo de batimologia. Um neologismo não é demais, se chegarmos à idéia de uma ciência nova: a dos escalonamentos da

linguagem. Essa ciência será inédita, pois ela abordará as instâncias habituais da expressão da leitura e da escuta ('verdade', 'realidade', 'sinceridade'); seu princípio será uma sacudida: ela passará por cima, como se pula um degrau, de toda expressão" (BARTHES, R. Roland Barthes por Roland Barthes. Tradução de Leyla Perrone-Moisés. São Paulo: Estação Liberdade, 2003, p. 80).]

21. "Looked at this way, films are only a series of documentary illustrations".

22. A citação de Kracauer foi retirada de Nature of film, reeditado em 1965 sob o título Theory of film.

\subsection{Níveis de funcionamento da leitura documentarizante}

A linguística da enunciação nos ensina que "quando interpretamos um enunciado" somos levados a reconhecer que ele exprime "uma pluralidade de vozes", que toda enunciação é, em graus diversos, “polifônica” (a expressão é de O. Ducrot, 1980)20.

Essa concepção plural de enunciação é capital para nossa proposição; só ela permite compreender como a leitura documentarizante pode se aplicar:

a. a um filme de ficção: para isso é suficiente, por exemplo, que o leitor, recusando-se a construir um Enunciador para a história contada, decida considerar o cenário que lhe é dado ver como um Enunciador real (como os cenários naturais);

b. a diferentes níveis de um mesmo filme (que seja ou não um documentário). Esse ponto requer um tanto de atenção.

Existem diferentes modos de pôr em ação a leitura documentarizante; de fato, há tantos modos de fazer operar a leitura documentarizante quantas são as possibilidades de construir, diante de um filme, Enunciadores reais.

Enumeramos algumas dessas possibilidades.

1. O leitor pode tomar a câmera como Enunciador real.

Nessa perspectiva, tudo o que se encontra diante da câmera (cenários, figurinos, personagens etc.) torna-se objeto da leitura documentarizante. Assim considerados, como observa sabiamente P. Sorlin (1980, p. 24), “os filmes não são senão uma série de ilustrações documentárias". ${ }^{21}$

Um dos melhores exemplos desse tipo de leitura sem dúvida é dado por S. Kracauer, para quem o cinema “é exclusivamente equipado para registrar e revelar a realidade física [...] A única realidade que nos interessa é a realidade realmente existente - o mundo transitório em que vivemos" (KRACAUER, 1965 apud SORLIN, 1980, p. 28) 22. 
2. O leitor pode tomar o cinema como Enunciador real. Evidentemente, esse é o tipo de leitura praticado pelos teóricos (historiadores, semiólogos) do cinema.

Um filme, escreve S. Heath (1981, p. 191-192), "é sempre um documento - um documentário - do filme e do cinema”; "todo filme é um documento de si próprio e de sua real situação a respeito da instituição cinemática e da complexidade da instituição social da representação" (p. 238).

3. O leitor pode tomar a Sociedade na qual o filme é produzido como Enunciador real. Aqui se reconhecem a leitura histórica (à la M. Ferro, 1977) e a leitura sociológica (à la P. Sorlin, 1977).

4. O leitor pode tomar o cameraman [o cinegrafista] como Enunciador real. É o caso típico do filme de reportagem. O pressuposto do leitor, nesse caso, é o de que o cameraman esteve no local onde os fatos aconteceram: ele os viu com os seus próprios olhos.

5. O leitor pode tomar o realizador do filme como Enunciador real.

Trata-se da leitura cinéfila, que faz de todo filme um documento sobre o seu "autor", ou ainda da leitura psicanalítica, a que já se fez alusão.

6. O leitor pode tomar o responsável pelo discurso, em posse do filme, como Enunciador real.

Esse responsável não se confunde com o realizador; em um filme pedagógico, por exemplo, a realização é assegurada por um profissional de cinema, mas a responsabilidade do discurso é do professor, do pesquisador ou do especialista que se exprime no filme (aquele que pressupostamente possui o Saber).

Poderíamos continuar por muito tempo essa enumeração, uma vez que são muitas as possibilidades de construir um Enunciador real; não há portanto uma leitura, mas várias leituras documentarizantes. 


\subsection{Alcance da leitura documentarizante}

A leitura documentarizante pode dizer respeito a um segmento mais ou menos importante do filme considerado.

Em relação ao eixo sintagmático temporal, primeiramente, a leitura documentarizante pode afetar um único fragmento do filme.

Em relação ao eixo sintagmático tópico, em seguida, quer dizer, em relação ao eixo das simultaneidades ${ }^{23}$, ela será concernente,

23. Sobre esta distinção, cf. METZ, C. Langage et cinéma. Larousse, 1971, p. 130-131. considerando que o leitor construirá um ou mais Enunciadores reais, a um ou mais estratos de filme: assim, um mesmo movimento documentarizante pode tomar como Enunciadores reais, ao mesmo tempo, a Sociedade, o cameraman, o realizador e o responsável pelo discurso do filme.

Enfim, nada impede que a leitura documentarizante funcione de forma descontínua, tanto em um nível como em outro; tanto de modo prolongado como de modo extremamente pontual.

De fato, uma grande flexibilidade preside a manifestação e a combinação das diferentes formas de leituras documentarizantes.

Tudo isso nos leva a interrogar as modalidades de produção dessas leituras.

\subsection{Modalidades de produção da leitura documentarizante}

Devem-se distinguir, acreditamos, dois grandes blocos de produção:

- $\quad$ a produção individual;

- a produção institucional.

\subsubsection{A produção individual}

Todo leitor tem a possibilidade, não importa em que momento do filme, de se conectar à leitura documentarizante. Sublinhamos, entretanto, que essa operação não pode sempre se efetuar em qualquer nível: o filme tem, com efeito, o poder de interditar certos níveis; é assim que a exibição, nos créditos, da participação dos atores bloqueia a possibilidade de construir personagens como 
Enunciadores reais (uma possibilidade que não relatamos até agora, mas que se manifesta especialmente no cinema direto). Convém, entretanto, insistir no fato de que um filme não tem jamais o poder de bloquear totalmente a leitura documentarizante - a qual pode sempre ao menos operar (mesmo no caso de filmes experimentais abstratos) no nível de construção da câmera e/ou do cinema, como Enunciadores reais.

Não deveríamos mais reduzir a produção da leitura documentarizante a um ato voluntário do leitor; ela pode surgir à sua revelia, de uma maneira totalmente súbita e improvisada, como uma "fissura na qual a duração não é mensurável nem previsível", durante o momento em que se assiste a um filme, e mesmo depois disso (parece-nos que é isso o que visa M. Bouvier com a sua noção de "primeiro documentário" [abord documentaire]).

\subsubsection{A produção institucional}

Existe um grande número de instituições que programam a leitura documentarizante dos filmes. Como prova disso, basta ver a enumeração que nós apresentamos das diferentes possibilidades de produção de um Enunciador real. A quase totalidade das leituras observadas remete a uma instrução do tipo institucional: instrução da instituição pedagógica, da instituição histórica, sociológica ou psicanalítica, instrução da instituição história do cinema ou análise de filmes...

Evidentemente, o espectador "em carne e osso" tem sempre a possibilidade de recusar a instrução institucional à qual ele é submetido (ele pode, por exemplo, se deixar encaminhar para a leitura fictivizante ainda que a instrução seja analisar o filme), mas, ao fazer isso frequentemente (não sempre, é claro), recai no golpe de uma outra instrução institucional: a leitura fictivizante é assim o resultado da aplicação da instrução da instituição cinematográfica dominante, instrução que interiorizamos de tal modo que temos dificuldade de modificá-la quando nos encontramos face a um filme que demanda ser lido segundo outro modo de leitura (leitura documentarizante ou outra). Este 
24. Nota do tradutor: Office Français des Techniques Modernes d'Éducation [Escritório Francês de Técnicas Modernas de Educação].

25. Nota do tradutor: Serdav (Service d'Étude de Réalisation et Diffusion de Documents Audiovisuels) [Serviço de Estudo de Realização e Difusão de

Documentos Audiovisuais], um setor do CNRS (Centre National de la Recherche Scientifique) [Centro Nacional de Pesquisa Científica], que, por sua vez, é relacionado ao CFE (Comité du Film Ethnografique) [Comitê do Filme Etnográfico], criado por Jean Rouch, Claude Lévi-Strauss e Henri Langlois, entre outros. último ponto, que pressupõe a existência de filmes que pedem para serem lidos segundo um modo de leitura determinada, nos conduz naturalmente a tentar precisar como se efetua, nesses mesmos filmes, a apresentação documentarizante; isso quer dizer voltar à definição de conjunto documentário.

N.B.: Perceber-se-á que nós falamos de conjunto documentário, e não de gênero documentário; é que a noção de gênero nos parece ser de um nível inferior ao da distinção que nós tentamos colocar aqui: com efeito, assim como existem gêneros no conjunto de filmes de ficção (western, policial, comédia musical etc.), também existem gêneros no conjunto documentário (filmes etnográficos, filmes industriais, filmes científicos etc.).

\section{O conjunto documentário}

Diremos que um filme pertence ao conjunto documentário quando ele integra explicitamente em sua estrutura (de um modo ou de outro) a instrução de fazer acionar a leitura documentarizante: quando ele programa a leitura documentarizante. Essa instrução pode se manifestar seja nos créditos, seja no próprio texto fílmico.

\subsection{O crédito como instrução de leitura documentarizante}

Vamos enumerar alguns casos:

- presença de uma legenda indicando claramente que se trata de um documentário: "uma reportagem de...", "uma enquete filmada...";

- presença de uma legenda designando uma estrutura de produção especializada em filme documentário: "Ofrateme ${ }^{24}$ apresenta...", “uma produção Serddav-CNRS. CFE. ${ }^{25 ” . . . ~ e t c . ; ~}$

- ausência de nomes de atores: é uma ausência que serve de marca; os linguistas e os semiólogos conhecem bem esse fenômeno; contudo, a ausência do nome de atores não pode funcionar como marca senão porque nós todos interiorizamos a norma do filme de ficção e porque esperamos dos créditos do filme que nos apresentem a lista dos atores que veremos; 
- forma do título: títulos como Notre planète la terre (Painlevé), Le tonnelier, Le charron (Rouquier), Bücherons de la Manouane (Lamothe) anunciam, sem ambiguidade, um documentário;

- ausência de crédito: essa marca por ausência evidencia um fraco nível de elaboração do texto fílmico proposto; o filme se mostra como não sendo nem uma obra nem uma mensagem: é um simples documento; essa figura, frequente nos filmes de família, encontra-se igualmente em certos filmes médicos, etnográficos etc.; note-se que, em geral, essa ausência de créditos anda de mãos dadas com a presença real dos realizadores do documento apresentado, no momento da projeção.

\subsection{As instruções textuais}

Um fato é certo: "um espectador - que entrasse de olhos fechados em uma sala onde se projetasse um filme sobre o qual ele jamais ouviu falar - , depois de alguns minutos, compreenderia se tratar de um filme de ficção ou de um documentário" (ZAGAGLIA, 1982, p. 178), mesmo que ele não tivesse visto os créditos.

Existe então figuras estilísticas típicas do documentário.

F. Pelletier (1983, p. 144) tem, entretanto, razão de sublinhar que as figuras estilísticas, elas mesmas, não atuam tanto no papel de instrução - “tomadas individualmente”, elas são “idênticas em cada domínio" - , quanto certos “agenciamentos estilísticos”, uma combinatória, uma estrutura de figuras.

É provável, além disso, que existam diferentes estruturas estilísticas suscetíveis de produzir uma leitura documentarizante.

Vamos esboçar rapidamente a análise de dois desses subconjuntos estilísticos:

- o subconjunto filmes pedagógicos;

- e o subconjunto filmes de reportagem. 


\subsubsection{O sistema estilístico do subconjunto filmes pedagógicos}

Foi descrito por G. Jacquinot em sua obra Image et pédagogie (1977). Lembremos as figuras essenciais:

- $\quad$ aparição na tela daquele que sabe (o professor ou o especialista);

- remissão direta do detentor do saber ao leitor ou a seu interlocutor no filme (o entrevistador);

- estruturação abstrata do representado pelo discurso:

- comentário do tipo explicativo;

- utilização de esquemas ou gráficos.

\subsubsection{O sistema estilístico do subconjunto filme de reportagem}

Os filmes de R. Depardon (Reporters, Numéro zéro, Faits divers) são exemplares desse subconjunto; eles podem servir de corpus de referência para a observação desse sistema estilístico.

As figuras seguintes, nos parece, podem ser consideradas:

- no nível da imagem: flou [foco embaçado], tremulação da imagem, travellings aos solavancos, panorâmicas hesitantes, golpes de zoom, rupturas brutais no desenvolvimento dos planos e no encadeamento das sequências, longos planossequências, iluminação deficiente, grão da película...

- no nível do som: timbre específico do som direto (por oposição ao som de estúdio: ausência de ressonância), ruído, estrutura linguística da palavra “viva”... (esse nível não está, evidentemente, sempre presente nos filmes de reportagem, pois existem reportagens silenciosas);

- no nível da imagem e/ou do som: direcionamento para o cameraman (as personagens filmadas olham para o câmera, interpelam-no, tomam partido...).

É significativo que seja precisamente esse conjunto de figuras que se encontra nos filmes de ficção que pretendem produzir uma ilusão de filmes de reportagem (que desejam produzir o que se 
26. Peter Watkins é um especialista em "falsas reportagens"; cf. Forgotten faces, Culloden, The war game; para explicações sobre o seu trabalho nesse tipo de filme, cf. sua entrevista em Le Cinéma Pratique, n. 67 , p. 114-121.

pode chamar de um "efeito reportagem"): Punishment Park, de P. Watkins ${ }^{26}$; L'Ambassade, de C. Marker; Zelig, de W. Allen... A função desse conjunto de figuras é clara: marcar na própria estrutura do filme a existência real do cameraman; fazer o espectador saber que o cameraman é tomado como Enunciador real. As figuras citadas evidenciam, especialmente, a dificuldade que teve o cameraman ao filmar nas condições em que ele se encontrava, o seu engajamento físico no evento, ou, ainda, o risco que ele sofreu.

Notar-se-á como sintomático desse subconjunto que a Ninfa de Ouro que premiou a melhor reportagem no Festival de Monte Carlo foi atribuída, em 1983, a um filme que inscreve em sua própria película a morte de seu cameraman: Jean Lugo - 4 juin 1982, Beyrouth, la mort d'un cameraman.

\section{Observação: subconjuntos vs gêneros}

Os subconjuntos dos quais acabamos de falar, e que se definem em termos de sistemas estilísticos, não devem ser confundidos com os gêneros documentários, definidos em termos de conteúdos e/ou de restrições pragmáticas.

É assim que o subconjunto que denominamos "reportagem" engloba documentários pertencentes a gêneros bem diferentes: documentários etnográficos, filmes de atualidade, reportagens de guerra, filmes de família... Nada, com efeito, distingue, por exemplo, no nível estilístico, os filmes de família de outros tipos de reportagem; a diferença não está nem mesmo no nível dos conteúdos veiculados (de fato, encontra-se de quase tudo nos filmes de família), mas nas condições pragmáticas particulares: a leitura dos filmes de família se faz por referência a uma diegese anterior ao filme (as lembranças do vivido) ${ }^{27}$. Igualmente, só um critério pragmático permite estabelecer a especificidade do gênero "atualidade" no interior do subconjunto "reportagem": os filmes de atualidade referem-se a acontecimentos recentes (na pior das hipóteses, da última semana). Reciprocamente, todos os filmes de um mesmo gênero não pertencem obrigatoriamente ao mesmo 
subconjunto estilístico: certos documentários etnográficos não se apresentam como "reportagens", mas como "filmes pedagógicos".

A relação subconjunto/gênero constitui então um caso típico de classificação cruzada.

\subsection{O funcionamento da instrução documentarizante}

Como na leitura documentarizante produzida de modo externo ao filme, a instrução documentarizante inscrita na estrutura do filme pode dizer respeito tão somente a certos níveis de funcionamento do filme.

Nos filmes documentários de reconstituição (ex. Le grand Méliès, de G. Franju; Lumière et l'invention du cinématographe, de P. Paviot), os créditos nos convidam a não considerar como Enunciadores reais os atores de fato, mas o responsável pelo discurso, aquele que garante a autenticidade dos eventos relatados e das palavras pronunciadas.

A instrução documentarizante dada por um filme pode então ser mais ou menos seletiva.

Existem assim uma escala documentária e níveis de "documentaridade", avaliáveis em termos do número de níveis convocados para a construção do Enunciador real: dito de outra forma, há documentários que são "mais documentários” que outros.

Existem também filmes híbridos, na interseção entre dois (ou mais) conjuntos cinematográficos, filmes que entrelaçam duas (ou mais) instruções de leitura (ex. Lettres de Somalie, de F. Mitterrand).

Enfim, existem filmes ambíguos, que não oferecem as instruções de forma clara a seus leitores (que não permitem determinar rapidamente quando e se convém fazer funcionar o modo documentário ou o modo ficcional) - exemplo: La pyramide humaine, de J. Rouch; Shadows, de J. Cassavetes - , e também filmes enganadores, que pegam os leitores na armadilha de sua competência textual: L'Ambassade, de C. Marker, será lido como uma reportagem até o último plano do filme, que revela que a ação se passa em Paris e remete ao ficcional tudo o que vinha de outro olhar. 
4. Dois tipos de conclusão podem resultar desse breve estudo:

- um diretamente ligado ao objeto deste artigo;

- $\quad$ outro, de sentido mais geral.

\subsection{Quatro grandes modos de produção da leitura documentarizante foram postos em evidência}

1. dois externos ao filme:

- $\quad$ a produção pelo leitor;

- $\quad$ e a produção pelas instituições sobre as quais se realiza a leitura do filme.

2. dois internos ao filme:

- a produção pelos créditos;

- $\quad$ e a produção pelo sistema estilístico do filme.

A distinção entre instruções externas e instruções internas é particularmente importante: ela permite especialmente explicar, por um lado, a instituição de espectadores que dividem o campo cinematográfico em conjuntos e reconhecem a existência de um campo documentário e, por outro, faz que todo filme seja susceptível a ser lido como um documentário.

Quanto à detecção dos diferentes níveis de leitura, definidos em termos da modalidade de construção do Enunciador, ela dá conta da diversidade de leituras que podem ser produzidas no quadro da leitura documentarizante.

4.2. Genericamente, todo ato de leitura aparece à luz daquilo que foi definido como uma operação que põe em ação um sistema interativo de três actantes:

- $\quad$ um filme, que demanda, mais ou menos urgentemente, mais ou menos explicitamente, ser lido segundo um ou outro modo de leitura; 
28. Para um exemplo de rejeição de um filme por uma instituição (nesse caso, instituição do filme de ficção),

cf. nosso artigo: "Mise en phase, déphasage et performativité dans

Le Tempestaire de Jean Epstein", Communications, n. 38, p. 213-238.
29. Para especificações sobre esse programa, cf. Roger Odin: "Pour une sémio-pragmatique du cinéma”, Iris, n. 1, 1983.
- uma instituição, que programa de um modo mais ou menos restritivo um ou outro modo de leitura;

- e um leitor, que reage à sua maneira às solicitações e instruções das duas outras instâncias.

Não é necessário que as relações entre esses três actantes sejam sempre de natureza pacífica: um filme pode ser rejeitado pela instituição na qual foi projetado ${ }^{28}$, o leitor pode recusar-se a jogar o jogo demandado pelo filme ou não se dar conta das determinações que a instituição faz pesar sobre si etc.; da mesma forma, seria falso acreditar que essas relações permanecem estáveis ao longo da leitura de um filme: às vezes, o leitor se conforma à demanda do filme; às vezes, à da instituição; às vezes, ele se deixa levar a outras determinações... a menos que mobilize simultaneamente vários modos de leitura...

Confrontado com esse jogo tripartite, o teórico não será levado pelas reações individuais e imprevisíveis dos leitores; em contrapartida, ele pode se colocar como tarefa a descrição das diferentes formas de instruções institucionais que intervêm no campo cinematográfico, e das suas inscrições no próprio sistema do filme (a demanda de um ou outro modo de leitura manifestada por um filme reflete, com efeito, a instrução institucional que funcionou no espaço da realização). Um tal estudo, que nós sugerimos denominar de "semiopragmático", acaba de começar... ele deverá ser capaz de dar conta tanto da heterogeneidade quanto da complexidade e da estruturação do campo cinematográfico em seu conjunto ${ }^{29}$. 


\section{Referências}

AUMONT, J. At al. Esthétique du film. [S. 1.]: Nathan Université, 1983.

BANGE, P. "Semiotique littéraire: sur fictionnalité". In: Regard sur la sémiologie contemporaine, Travaux XXI. [S.l.]: Cierec-Université de Saint-Etienne, 1978.

BENVENISTE, E. Problèmes de linguistique générale, 1. [S.l.]: Gallimard, col. TEL [s. d.].

BÜHLER, K. Sprachtheorie. [S.l.: s.n.], 1934.

DUCROT, O. Les mots du discours. Paris: Minuit, 1980.

FERRO, M. Cinéma et histoire. Paris: Denoel/Gontier, 1977.

GAUTHIER, G. Texto introdutório. Image et Son, n. 183, (“Un cinéma de la réalité"), abril, 1965.

HAMBURGER, K. Logik der dichtung. Stuttgart: [s.n.], 1968.

HEATH, S. Questions of cinema. [S.l.]: Macmillan Press, 1981.

JACQUINOT, G. Image et pédagogie. Paris: PUF, 1977.

PELLETIER, F. Imaginaire du cinématographe. Paris: Librairie des Méridiens, 1983.

SCHMIDT, S. J. "La communication littéraire”. In: Stratégies discursives. PUL, 1978.

SEARLE, J. "Le statut logique du discours de la fiction". In: SEARLE, J. Sens et expression. Paris: Minuit, 1979.

SORLIN, P. Sociologie du cinéma. Paris: Aubier, 1977. The film in history. Oxford: Basil Blackwell, 1980.

ZAGAGLIA, P. “Naissance d'un genre: le documentaire-fiction”. In: Cinéma et réalité: Centre de l'Audiovisuel, Vie Ouvrière, Bruxelas, 1982. 